Development

\title{
Perturbation of Serotonin Homeostasis during Adulthood Affects Serotonergic Neuronal Circuitry
}

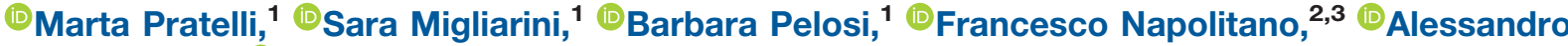 \\ Usiello, ${ }^{2,4}$ and ${ }^{-}$Massimo Pasqualetti ${ }^{1,5,6}$
}

DOI:http://dx.doi.org/10.1523/ENEURO.0376-16.2017

${ }^{1}$ Department of Biology Unit of Cell and Developmental Biology, University of Pisa, Pisa 56127, Italy, ${ }^{2}$ Ceinge Biotecnologie Avanzate, Naples 80145, Italy, ${ }^{3}$ Department of Molecular Medicine and Medical Biotechnology, University of Naples Federico II, 80131 Naples, Italy, ${ }^{4}$ Department of Environmental, Biological and Pharmaceutical Sciences and Technologies, University of Campania, Luigi Vanvitelli, Italy, ${ }^{5}$ Center for Neuroscience and Cognitive Systems, Istituto Italiano di Tecnologia, Rovereto, TN 38068, Italy, and ${ }^{6}$ Neuroscience Institute, National Research Council (CNR), Pisa 56124, Italy

\section{Visual Abstract}

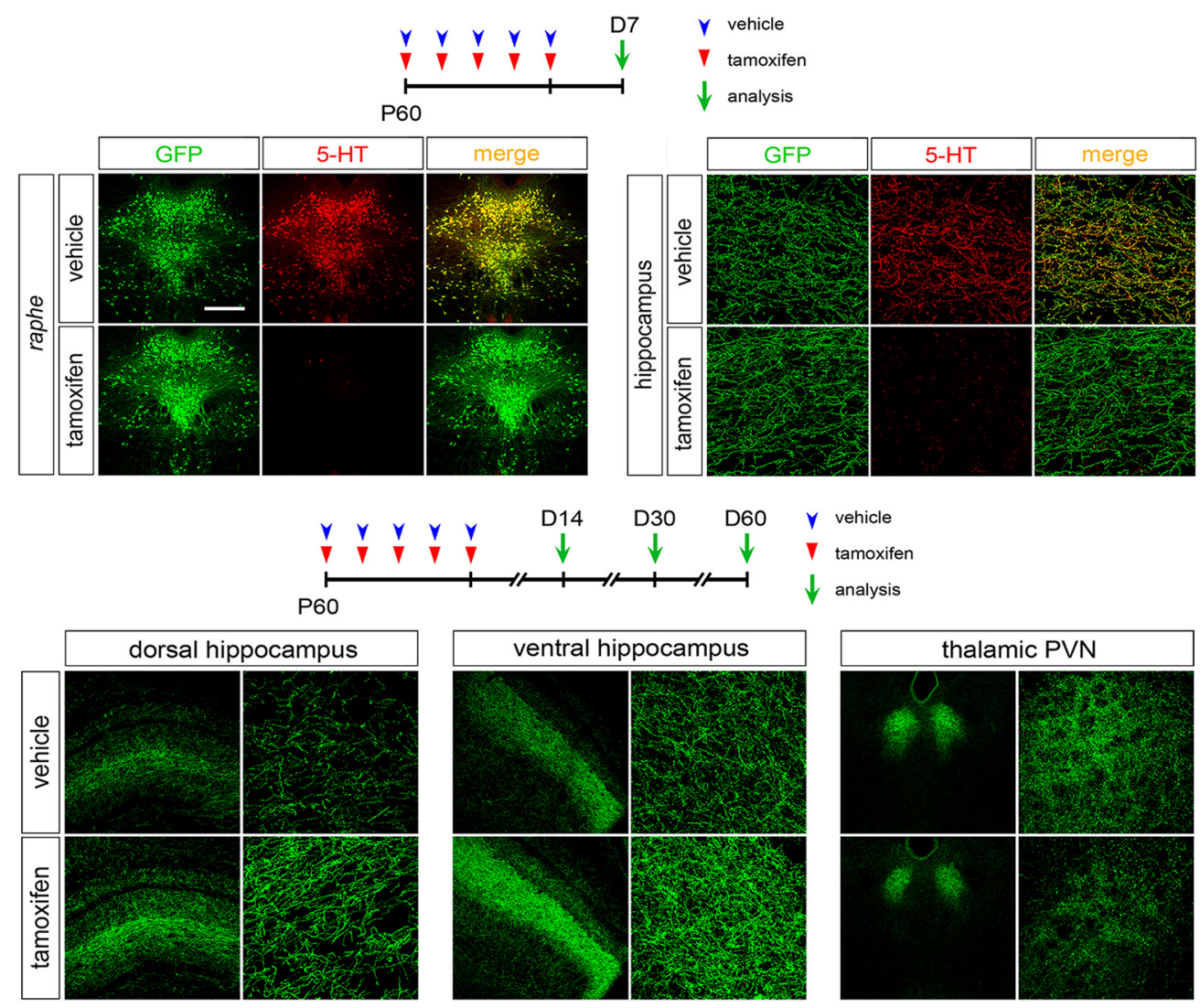

\section{Significance Statement}

Alterations in brain serotonin (5-HT) levels during development can interfere with neuronal circuitry establishment and contribute to behavioral disturbances in adult life. It remains enigmatic whether wiring patterns can be reshaped by fluctuations of 5-HT content in the adult brain. In this study, we show for the first time that the adult serotonergic circuitry is susceptible to perturbations of serotonin homeostasis. These results provide evidence of life-long requirement of proper 5-HT levels to preserve the serotonergic axonal wiring. 
Growing evidence shows that the neurotransmitter serotonin (5-HT) modulates the fine-tuning of neuron development and the establishment of wiring patterns in the brain. However, whether serotonin is involved in the maintenance of neuronal circuitry in the adult brain remains elusive. Here, we use a Tph $2^{f l o x}$ conditional knockout (cKO) mouse line to assess the impact of serotonin depletion during adulthood on serotonergic system organization. Data show that the density of serotonergic fibers is increased in the hippocampus and decreased in the thalamic paraventricular nucleus (PVN) as a consequence of brain serotonin depletion. Strikingly, these defects are rescued following reestablishment of brain 5-HT signaling via administration of the serotonin precursor 5-hydroxytryptophan (5-HTP). Finally, 3D reconstruction of serotonergic fibers reveals that changes in serotonin homeostasis affect axonal branching complexity. These data demonstrate that maintaining proper serotonin homeostasis in the adult brain is crucial to preserve the correct serotonergic axonal wiring.

Key words: 5-hydroxytryptophan; serotonergic innervations; serotonin; serotonin homeostasis; tryptophan hydroxylase 2

\section{Introduction}

Serotonin (5-hydroxytryptamnine, 5-HT) is a monoaminergic neuromodulator that orchestrates a broad array of processes from autonomic, cognitive and behavioral functions to the modulation of specific morphogenetic events during neurodevelopment (Gaspar et al., 2003; Ruhé et al., 2007; Alenina et al., 2009; Daubert and Condron 2010; Asan et al., 2013; Migliarini et al., 2013; Suri et al., 2015).

Neurons that synthetize serotonin are specified early during embryogenesis in the mouse hindbrain, where they cluster to form B1 to B9 raphe nuclei. Despite the fact that serotonergic neurons are relatively few in number $(25,000$ in mice; Ishimura et al., 1988), long-range projections and highly collateralized axons allow them to establish diffuse axonal trajectories to innervate the whole CNS (Gagnon and Parent 2014). By the end of gestation, serotonergic axon terminals have reached all the brain regions that will receive serotonergic innervation, and during the first three postnatal weeks, they actively sprout to profusely innervate their targets (Lidov and Molliver, 1982; Wallace and Lauder, 1983).

Received December 19, 2016; accepted February 17, 2017; First published April 3, 2017.

The authors declare no competing financial interests.

Author contributions: M.Pr., S.M., B.P., and M.Pa. designed research; M.Pr., S.M., B.P., F.N., A.U., and M.Pa. performed research; M.Pr., S.M., F.N., A.U., and M.Pa. analyzed data; M.Pr., B.P., and M.Pa. wrote the paper.

This work was supported by Italian Ministry of Education, University and Research (MIUR) (Prin 2008, 200894SYW2), Toscana Life Sciences Foundation (Orphan_0108 program), and Norwegian Research Council (to M.Pa.). B.P. and M.Pr. were supported by the PhD Program from University of Pisa. S.M. was supported by the Regional Program and European Social Fund.

Barbara Pelosi's present address: Laboratory of Neural Differentiation, Institute of Neuroscience, UCL, Brussels, 1200, Belgium.

Acknowledgments: We thank C. Valente for excellent technical assistance and members of our laboratory for valuable discussions and comments on the manuscript. We also thank Dr. P. Chambon and Dr. D. Metzger for the CMV-CreER ${ }^{\top}$ mouse line.

Correspondence should be addressed to Massimo Pasqualetti, University of Pisa, Department of Biology, Unit of Cell and Developmental Biology, Strada statale 12 Abetone e Brennero, Pisa 56127, Italy. E-mail: massimo.pasqualetti@ unipi.it.

DOI:http://dx.doi.org/10.1523/ENEURO.0376-16.2017

Copyright $\odot 2017$ Pratelli et al.

This is an open-access article distributed under the terms of the Creative Commons Attribution 4.0 International license, which permits unrestricted use, distribution and reproduction in any medium provided that the original work is properly attributed.
Maternal and placental sources of serotonin are essential for the development of the fetus (Côté et al., 2007; Bonnin et al., 2011; Goeden et al., 2016). This evidence, along with the early presence of serotonergic receptors in the developing brain, suggests that $5-\mathrm{HT}$ plays a role in the orchestration of specific neurodevelopmental events (Lauder, 1993; Gaspar et al., 2003). Indeed, it has been extensively reported that an appropriate serotonergic neurotransmission is essential for the correct development of the CNS. Examples emerged from studies on animal models in which a perturbation of 5-HT homeostasis was obtained by inactivating genes coding for the serotonin transporter (SERT) or for the monoamine oxidase A. In these mice, an excess of brain serotonin during early development resulted in the disruption of topographically organized whisker-barrel fields in the somatosensory cortex (Cases et al., 1996; Persico et al., 2001) and in an abnormal migration of cortical neurons (Riccio et al., 2009; Murthy et al., 2014). Interesting insights into the role of serotonin during neurodevelopment derived also from the generation of tryptophan hydroxylase 2 knockout (Tph2 KO) mice, in which the rate-limiting enzyme for serotonin biosynthesis in the CNS was inactivated (Savelieva et al., 2008; Alenina et al., 2009; Gutknecht et al., 2012; Migliarini et al., 2013). Although these mice failed to show gross brain malformations, a broad number of alterations was identified, suggesting that serotonergic signaling is essential for the fine-tuning modulation of neurodevelopmental events. Indeed, Tph2 KO mice showed physiologic modifications, altered behavior, impaired adult neurogenesis in response to running, and severe alterations in serotonergic circuitry development (Klempin et al., 2013; Migliarini et al., 2013; Mosienko et al., 2015).

Regarding the latter aspect, an important question that remains to be addressed is whether serotonin, besides its trophic role during development, is also required in the adult brain for the maintenance of serotonergic circuitry. Here, we used a Tph $2^{f l o x}$ conditional KO (cKO) mouse line to test whether severe unbalances in brain 5-HT neurotransmission during adulthood could affect the organization of serotonergic circuitry. We show that the disruption of 5-HT synthesis in adult mice deeply affects serotonergic innervation of rostral brain targets with a region-specific effect, and that a close-to-normal innervation pattern is reestablished when brain serotonin signaling is restored 
by chronic administration of the serotonin precursor 5-hydroxytryptophan (5-HTP). On the whole, these results prove that an appropriate serotonin homeostasis is crucial for the maintenance of serotonergic circuitry during adult stages of life.

\section{Materials and Methods}

\section{Animals}

Animals were maintained on artificial $12 / 12 \mathrm{~h}$ light/dark cycle at constant temperature of $22 \pm 1^{\circ} \mathrm{C}$ and were housed in standard Plexiglas cages with food and water ad libitum. All experimental protocols were conducted in accordance with the Ethic Committee of the University of Pisa and approved by the Veterinary Department of the Italian Ministry of Health.

To allow detection of serotonergic fibers independently of 5- $\mathrm{HT}$ immunoreactivity and to abrogate serotonin synthesis in a time-controlled manner, Tph2 ${ }^{\text {GFP/flox }:: C M V C r e E R^{T}}$ mice were generated (Feil et al., 1996, RRID: MGI_2387570; Migliarini et al., 2013, RRID: MGI_5442773; Pelosi et al., 2015, RRID: MGI_5823194). Animals were on C57BL/6 background obtained by backcrossing with C57BL/6 mice for at least nine generations.

All animals used in the experiments were males. Mice from the same litter were treated with either drugs or vehicle/saline and samples were processed in parallel to minimize treatment-independent variability.

\section{Pharmacological treatments}

Tph2 ${ }^{\text {GFP/flox::CCMVCreER }}{ }^{T}$ mice were injected intraperitoneally once a day starting at postnatal day 60 (P60) for five consecutive days with $75 \mathrm{mg} / \mathrm{kg}$ body weight tamoxifen (TM, Sigma-Aldrich) dissolved in sunflower oil/ethanol (1:9) as previously described (Pelosi et al., 2015). In parallel, littermates of the same genotype were injected with sunflower oil/ethanol (1:9; vehicle) and were used as controls.

Mice were chronically administered with 5-HTP for 30 consecutive days starting form three months of age for Tph2 ${ }^{\text {GFP }}$ mutant mice, and 30 days after the last TM-

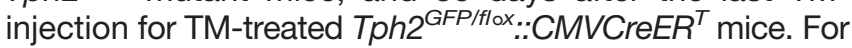
chronic 5-HTP treatment, mice were intraperitoneally injected twice a day (9 A.M. to 7 P.M.) with 5-HTP (SigmaAldrich; $20 \mathrm{mg} / \mathrm{kg}$ ) dissolved in sodium chloride $0.9 \%$ (saline) for 30 consecutive days. In parallel, to prevent an excessive decline in 5-HT concentration few hours after intraperitoneal injections (Mosienko et al., 2015), animals received a supplementation of 5-HTP dissolved in drinking water. 5-HTP concentration in drinking water was calculated to reach the final dose of $300 \mathrm{mg} / \mathrm{kg} / \mathrm{d}$, taking into account the weight of the animal and the average amount of water consumed daily. Control animals of the same litter were injected with saline and received water not supplemented with 5-HTP.

Immunohistochemistry and in situ hybridization (ISH)

Immunohistochemistry and ISH were performed following standard protocols (Pelosi et al., 2014). Briefly, for immunohistochemistry, animals were deeply anesthetized with intraperitoneal injection of Avertin (1.25\% solution of
2, 2, 2-tribromoethanol, Sigma-Aldrich) at $0.02 \mathrm{ml} / \mathrm{g}$ body weight and perfused transcardially with PBS followed by 4\% paraformaldehyde (PFA). Brains were dissected out and postfixed overnight $(\mathrm{o} / \mathrm{n})$ at $4^{\circ} \mathrm{C}$ in $4 \%$ PFA before being sectioned with a vibratome (Leica Microsystem) to obtain $50-\mu \mathrm{m}$-thick coronal sections. Free-floating sections were cryoprotected and a one-in-three series of sections for each brain was incubated with primary antibody.

To detect 5-HT and GFP colocalization in serotonergic neurons and fibers, sections were incubated o/n at $4^{\circ} \mathrm{C}$ with a solution of rabbit anti-5-HT (1:500, Sigma-Aldrich, RRID: AB_477522) and chicken anti-GFP (1:1000, Abcam, RRID: AB_300798) primary antibodies in PBS containing $5 \%$ heat-inactivated lamb serum and $0.5 \%$ Triton X-100. Section were then incubated $o / n$ in the same solution containing Rhodamine Red-X goat anti-rabbit IgG 1:500 (Thermo Fisher Scientific, RRID: AB_10374436) and Alexa Fluor 488 goat anti-chicken IgG 1:200 (Thermo Fisher Scientific, RRID: AB_2534096) secondary antibodies. For the analysis of serotonergic fibers, brain sections were immunostained for GFP using a rabbit anti-GFP primary antibody (1:2000, Invitrogen, RRID: AB_221570). To avoid the interference of endogenous GFP fluorescence in the relative optical density (ROD) quantification, a Rhodamine Red-X-conjugated goat anti-rabbit IgG antibody was used (1: 500, Thermo Fisher Scientific, RRID: AB_10374436). To determine background fluorescence adjacent sections were processed omitting the primary antibody. Cell nuclei were counterstained with DAPI $0.5 \mathrm{mg} / \mathrm{ml}$ (Sigma-Aldrich).

For SERT labeling, sections were first incubated for 30 min in $0.05 \%$ hydrogen peroxide in PBS and $0.03 \%$ Triton $X-100$ to block endogenous peroxidase activity, and subsequently incubated for $36 \mathrm{~h}$ with a rabbit anti-SERT antibody (1:500, Millipore, RRID: AB_612176) in PBS containing $10 \%$ heat-inactivated lamb serum and $0.3 \%$ Triton $X-100$. To achieve signal amplification the avidin-biotinHRP conjugate solution (VECTASTAIN Elite ABC kit, Vector Labs, RRID: AB_2336810) was used, following the manufacturer's instructions. Staining was obtained by a 10-min incubation with 3-30 diaminobenzidine tetrahydrochloride (Sigma-Aldrich). For ISH, brains were dissected out, embedded in TISSUE Tek (Sakura), frozen on dry ice, and stored at $-80^{\circ} \mathrm{C}$. Coronal $14-\mu \mathrm{m}$-thick sections were cut using a cryostat and ISH was performed accordingly to standardized protocols using $\mathrm{a}^{35} \mathrm{~S}$-labeled $B D N F$ antisense RNA probe previously described (Migliarini et al., 2013). Sections were then exposed to Biomax MR x-ray films (Kodak) for $2 \mathrm{~d}$.

\section{Western blot analysis}

For Western blot analysis, mice were killed by decapitation, and the hippocampus was dissected out, frozen in liquid nitrogen, and stored at $-80^{\circ} \mathrm{C}$. Hippocampal samples were sonicated in a lysis buffer $(320 \mathrm{mM}$ sucrose, 50 $\mathrm{mM}$ Tris $\mathrm{HCl}, \mathrm{pH} 7.5,50 \mathrm{mM} \mathrm{NaCl}, 1 \%$ Triton X-100, 5 $\mathrm{mM} \beta$-glycerol phosphate, $1 \mathrm{mM} \mathrm{Na}_{3} \mathrm{VO}_{4}, 5 \mathrm{mM} \mathrm{NaF}$, protease inhibitor cocktail) and, after a 30 -min incubation in ice and 10 -min spinning at $12,000 \times g$, the supernatant was collected. After protein determination by Bio-Rad 
Protein Assay kit (Bio-Rad), equal amounts of total proteins $(30 \mu \mathrm{g})$ for each hippocampal sample were loaded onto both $10 \%$ and $15 \%$ polyacrylamide gels to determine BDNF and tyrosine receptor kinase B (TrkB) levels, respectively. Proteins were separated by SDS-PAGE and transferred overnight to membranes (Immobilon PVDF Membrane, Millipore). Then, membranes were immunoblotted overnight using selective antibodies against BDNF (1:500, Santa Cruz Biotechnology, RRID: AB_630940) and TrkB (1:1000, Santa Cruz Biotechnology, RRID: $\left.A B \_2155274\right)$. Blots were then incubated with appropriate HRP-conjugated secondary antibody and target proteins were visualized by ECL detection (GE Health Care), followed by quantification through Quantity One software (Bio-Rad, RRID: SCR_014280). All optical density values of BDNF and TrkB were normalized using an antibody against GAPDH (1:5000, Santa Cruz Biotechnology, RRID: AB_627679) and $\alpha$-tubulin (1:50,000, Sigma-Aldrich, RRID: AB_477593), respectively.

\section{Images analysis and quantification}

Analysis of serotonergic fiber density was conducted on coronal brain sections immunostained for GFP. All the pictures were randomized before signal quantification, and the operator who performed the analysis was blinded to genotype and treatment.

The density of serotonergic fibers was manually quantified by ROD measurements following the procedure previously described by Migliarini et al. (2013). Images were taken with Eclipse Ti microscope (Nikon) using $10 \times$ or $4 \times$ objectives depending on the brain structure under analysis and constant acquisition parameters, and using both rhodamine and DAPI filter. Images were then converted to gray-scale (8-bit) and the optical density (OD) was quantified within the area of interest in both hippocampus and thalamic paraventricular nucleus (PVN) taking advantage of the DAPI staining using ImageJ software (RRID: SCR_003070). To calculate ROD values, the background fluorescence was subtracted from the measured OD. Background fluorescence was assessed by measuring the OD on control adjacent sections processed omitting the primary antibody.

To measure the intensity of GFP immunosignal within serotonergic neurons, images were acquired with a Nikon-A1 confocal microscope using a $10 \times$ objective and constant acquisition parameters. Images were composed of $17 \mathrm{z}$-stacks obtained at $0.3-\mu \mathrm{m}$ step size (voxel size of $1.24,1.24$, and $1 \mu \mathrm{m} /$ pixel in $x-, y$-, and $z$-dimensions, respectively). For each animal, three representative images of the median and dorsal raphe nuclei were acquired and the intensity of GFP fluorescence within 5-HT neurons was measured using the Surface tool of the Imaris Bitplane software (version 7.2.3, RRID: SCR_007370).

For the quantification of $B D N F$ mRNA expression in the hippocampus, autoradiography films resulting from radioactive ISH were scanned at a resolution of $3200 \mathrm{dpi}$. The $\mathrm{OD}$ values were evaluated using the ImageJ software in the pyramidal cell layer of Ammon's horn (CA) and in the granule cell layer of the dentate gyrus (DG) of the hip- pocampus. To obtain the ROD value, for each analyzed section the background OD was determined in structures of the same section devoid of signal. At least five sections for each animal were quantified.

For 3D morphologic analysis of serotonergic fibers, high-magnification confocal images were acquired using a Nikon-A1 confocal microscope. Acquisitions were performed using a $60 \times$ objective at a digital zoom of 3.0 and were composed of $60 \mathrm{z}$-stacks obtained at $0.3 \mu \mathrm{m}$ step size (voxel size of $0.07,0.07$, and $0,3 \mu \mathrm{m} / \mathrm{pixel}$ in $x-, y-$, and $z$-dimensions, respectively). For each animal, three consecutive sections from a one-in-three series along the antero-posterior axis were analyzed performing the acquisitions at the level of the stratum lacunosum moleculare using the same dorso-ventral and lateral coordinates. Accordingly to the procedure described by Scott et al. (2013), the semiautomatic fiber tracking software Imaris Bitplane (version 7.2.3, RRID: SCR_007366) was used to generate a 3D map of serotonin axons. Computer-based quantifications of morphologic parameters such as axon length (AL), axon mean diameter, number of axon branch points and tortuosity index were automatically performed by Imaris software on the reconstructed fibers.

\section{Statistical analysis}

Tests of significance for two-sample comparisons were performed using two-tailed Wilcoxon singed rank exact test for paired data or two-tailed Student's $t$ test. For three-sample comparison, we used Friedman test followed by two-tailed Wilcoxon signed rank exact test. For 3D reconstruction of GFP-positive fibers, Friedman test followed by one-tailed Wilcoxon signed rank exact test was used. Bonferroni's correction was applied in case of multiple comparisons; $p<0.05$ was considered statistically significant.

\section{Results}

\section{Depletion of serotonin in the adult brain results in the alteration of serotonergic innervation density}

To address the consequences of serotonin depletion in adulthood, we took advantage of the combination of two mouse lines. We used the Tph2 $2^{f l o x}$ inducible KO allele, in which Tph2 exon 3 has been floxed allowing the abrogation of serotonin synthesis on time-specific Cre recombinase activity following TM administration (Pelosi et al., 2015). We also took advantage of the Tph2::eGFP knockin mouse line (defined Tph2 ${ }^{\text {GFP }}$ from now on), in which the substitution of the Tph2 gene with the GFP cDNA results in both the disruption of Tph2 expression and the expression of the fluorescent reporter mirroring the presence of serotonin in both somata and projections of serotonergic neurons in developing and adult animals (Migliarini et al., 2013). By intercrossing the two lines, we obtained Tph2 ${ }^{G F P / f l o x}$ trans-heterozygous mice, harboring an inactive Tph $2^{\text {GFP }}$ knockin allele and a $T p h 2^{\text {flox }}$ allele that can be inactivated on Cre-mediated somatic recombination. Tph2 ${ }^{\text {GFP/flox }}$ trans-heterozygous mice were born at normal Mendelian ratios and lived a normal lifespan without showing any obvious defect. To conditionally ablate serotonin synthesis in adult animals, we then inter- 


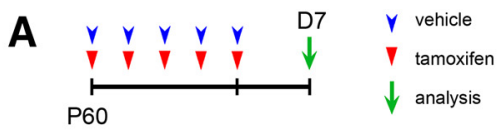

B

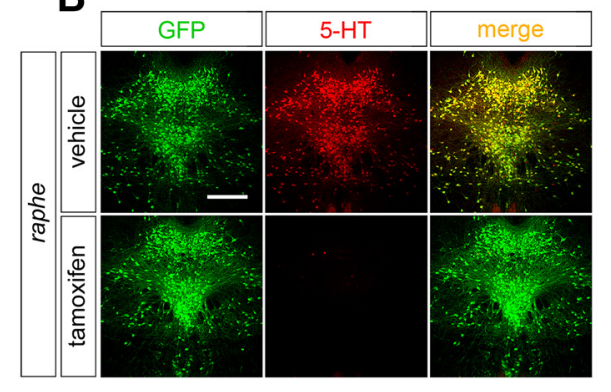

GFP

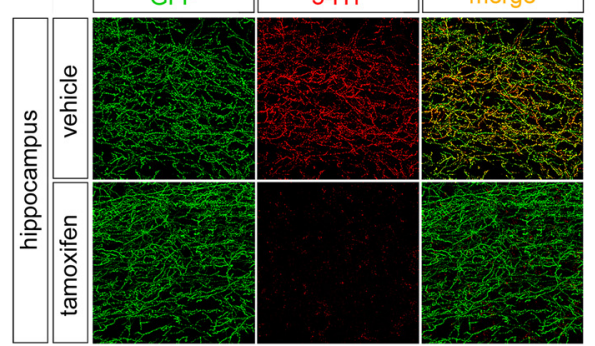

C

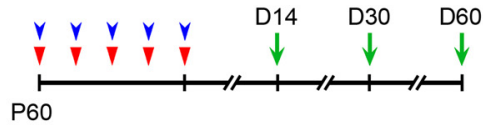

E
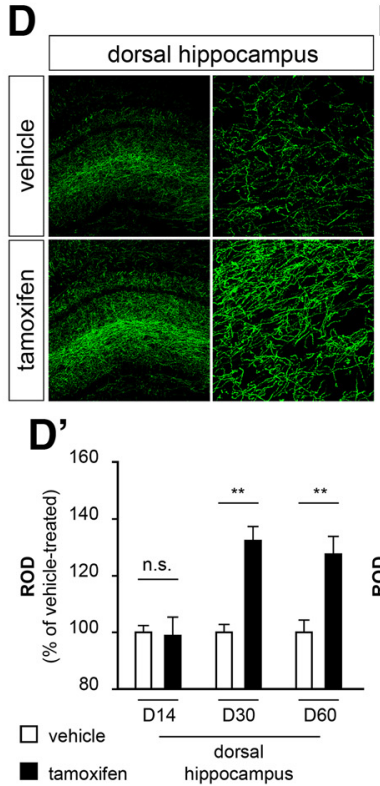

$\checkmark$ vehicle
$\nabla$ tamoxifen
$\downarrow$ analysis

$\mathbf{F}$
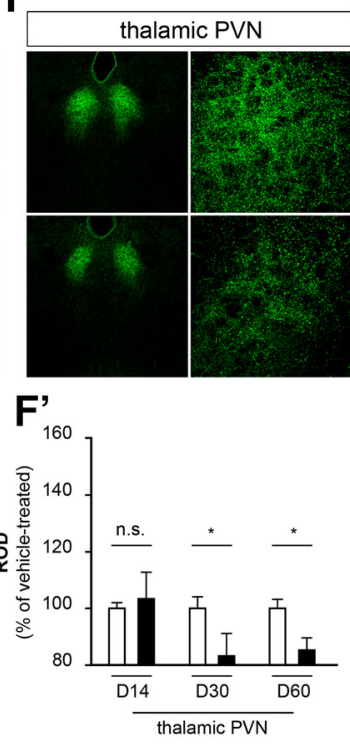

Figure 1. 5-HT depletion in adult mice affects the density of serotonergic fibers that innervate the hippocampus and the thalamic PVN. $\boldsymbol{A}$, Experimental timeline of TM treatment in Tph2 ${ }^{G F P / f l o x}:: C M V C r e E R^{T}$ mice. $\boldsymbol{B}$, Representative images of raphe nuclei (top panel) and hippocampus (bottom panel) highlighting the depletion of serotonin within serotonergic cell bodies and fibers, respectively. $\boldsymbol{C}$, Experimental timeline of serotonergic fiber density analysis. $\boldsymbol{D}-\boldsymbol{F}$, Representative coronal sections immunostained for GFP showing the distribution of serotonergic fibers in the dorsal hippocampus, ventral hippocampus, and in the thalamic PVN of vehicle- and TM-treated mice at D30. High-magnification images are shown on the right column of each panel. $\boldsymbol{D}^{\prime}-\boldsymbol{F}^{\prime}$, Quantification of serotonergic fiber density in the hippocampus and in the thalamic PVN of TM- and vehicle-treated mice. Quantitative analyses were performed by means of ROD measurements at D14 ( $n=4$ for each treatment), D30 ( $n=7$ for the hippocampus; $n=5$ for the thalamic PVN), or D60 ( $n=8$ for the hippocampus; $n=6$ for the thalamic PVN). Data are presented as percentage increase/decrease of ROD values of TM-treated mice as compared with vehicle-treated controls \pm SEM. Wilcoxon singed rank test for paired data were used as test of significance. $* * p<0.01$; $* p<0.05$; n.s., not significant, $p>0.05$. Scale bar, $350 \mu \mathrm{m}(\boldsymbol{B}$, top panels; $\boldsymbol{D}-\boldsymbol{F}$, left panels), 60 $\mu \mathrm{m}$ ( $\boldsymbol{B}$, bottom panels), $30 \mu \mathrm{m}$ ( $\boldsymbol{D}-\boldsymbol{F}$, right panels).

crossed Tph $2^{\text {GFP/flox }}$ mice to the CMVCreER ${ }^{T}$ mouse line to obtain Tph2 ${ }^{\text {GFP/flox:::CMVCreER }}{ }^{T}$ mice, in which Cre recombinase transcription is driven by a cytomegalovirus promoter and its site-specific DNA recombination activity is conditionally activated on administration of TM (Feil

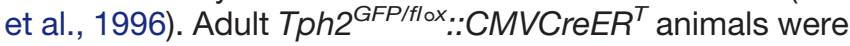
treated at P60 with TM once a day for five consecutive days to deplete serotonin synthesis as previously described (Pelosi et al., 2015). TM-treated Tph2 GFP/flox:: $C M V C r e E R^{T}$ mice, analyzed one week after the end of TM treatment, showed an almost complete loss of serotonin immunoreactivity in the raphe nuclei as previously shown (Pelosi et al., 2015) as well as in serotonergic terminals reaching the rostral brain, as compared with vehicletreated control mice (Fig. $1 A, B$ ).

As lack of central serotonin in Tph $2^{\text {GFP }}$ mutants has been shown to affect serotonergic fiber sprouting in the hippocampus, the nucleus accumbens, the suprachiasmatic nucleus, and the thalamic PVN with a regionspecific effect (Migliarini et al., 2013), we asked whether the conditional removal of this monoamine in adulthood could result in similar alterations. We thus compared the organization of GFP-positive serotonergic fibers in TM- versus vehicle-treated Tph2 $2^{G F P / f l o x}:: C M V C r e E R^{T}$ animals, 14,30 , or 60 days after the last TM injection (D14, D30, and D60, respectively; Fig. 1C), and we focused our analysis on two brain regions such as the hippocampus and the thalamic PVN that showed pronounced and opposite alterations in Tph2 ${ }^{\mathrm{GFP}}$ mutant mice (Migliarini et al., 2013). Analysis of ROD at D14 showed no significant changes in serotonin innervation between the two treatment groups in both dorsal and ventral hippocampus as well as in thalamic PVN (Fig. 1 $D^{\prime}-F^{\prime}$ ). Strikingly, at D30, GFPimmunoreactive fiber density appeared to be increased in the hippocampus of TM-treated mice as compared with vehicle-treated matched controls (Fig. 1D,E). Quantitative analysis by means of ROD measurements showed a $32 \%$ significant increase in the dorsal hippocampus and $42 \%$ in the ventral part $\left(p<0.01\right.$; Fig. $\left.1 D^{\prime}, E^{\prime}\right)$. Conversely, the extension and density of immunoreactive serotonergic fibers appeared reduced in the thalamic PVN of D30 TM-treated animals, as confirmed by ROD analysis $\left(-18 \%, p<0.05\right.$; Fig. $\left.1 F, F^{\prime}\right)$. To assess whether the observed alterations in ROD values could be linked to changes in GFP expression due to a different regulation of the Tph2 promoter following 5-HT depletion, we mea- 
A
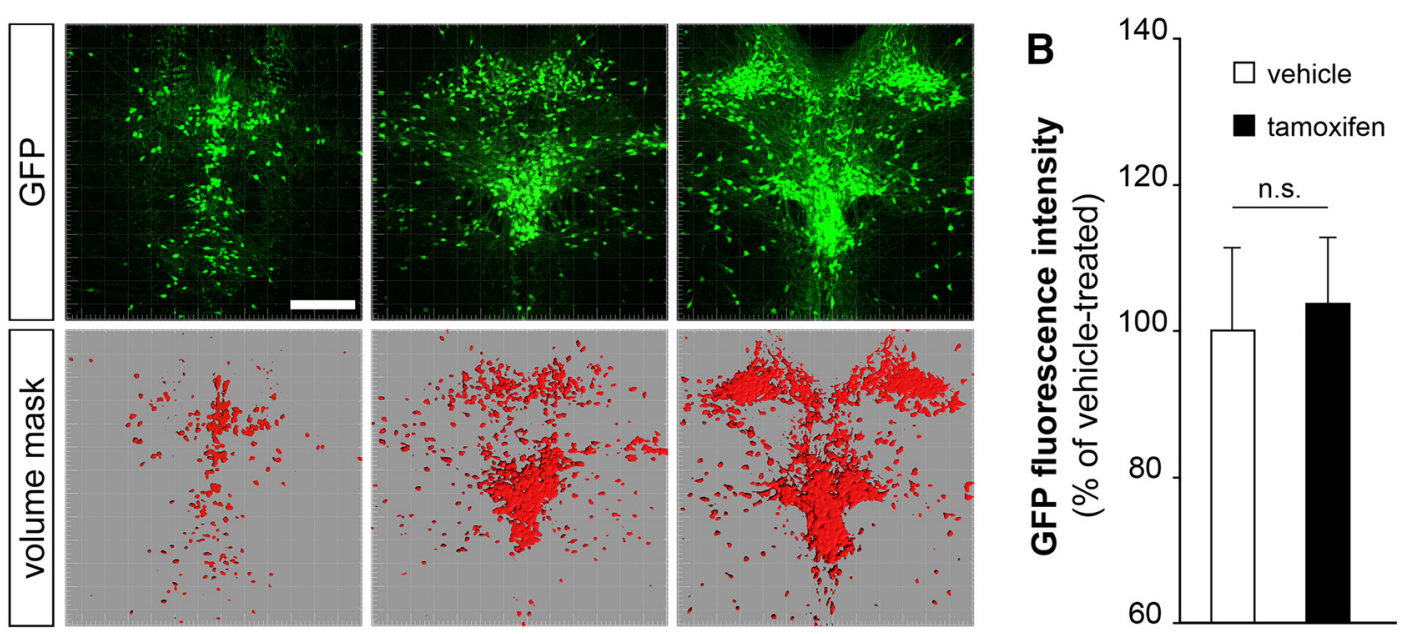

\section{C}
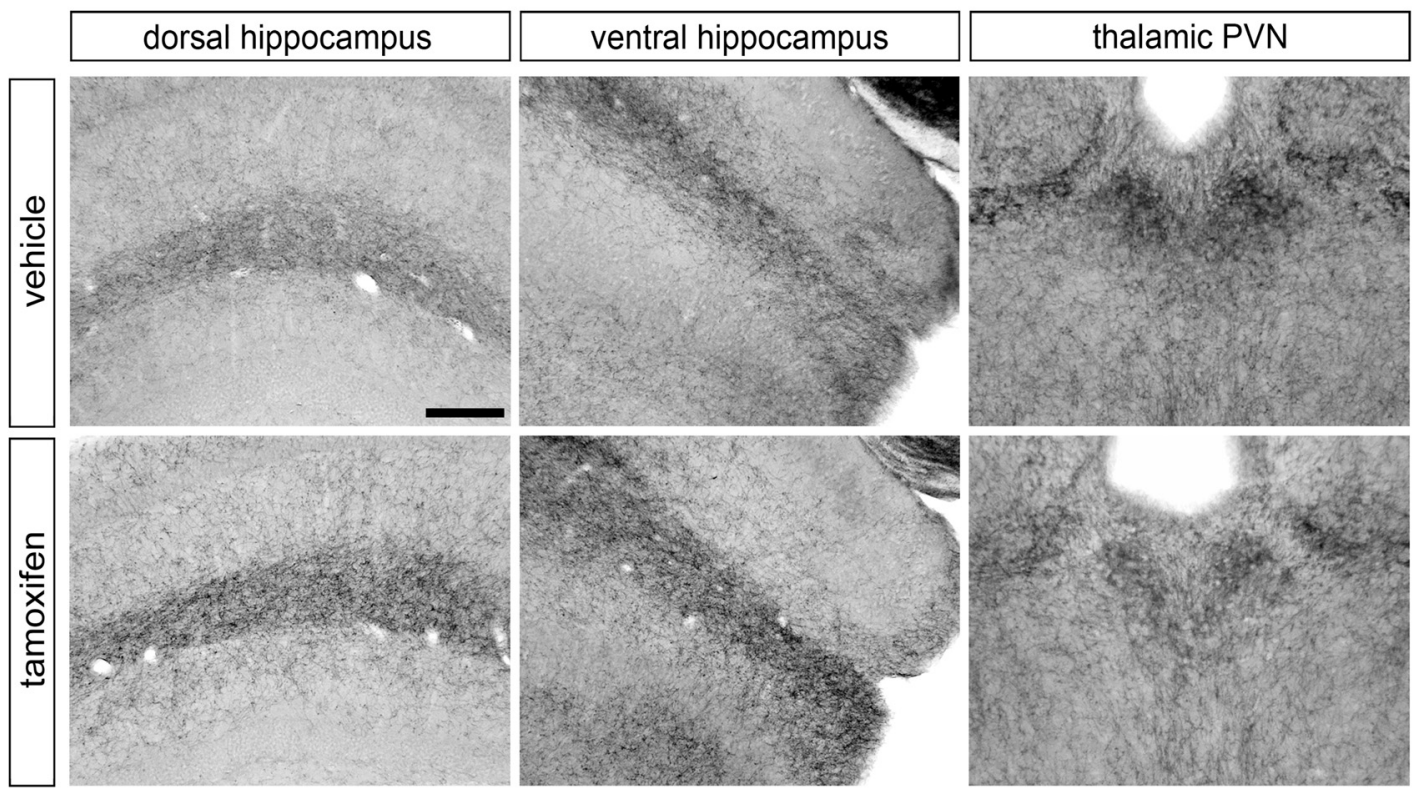

Figure 2. Alterations in the density of serotonergic fibers cannot be ascribed to changes in GFP expression in TM- versus vehicle-treated mice. $\boldsymbol{A}$, Representative images showing the levels along the antero-posterior axis where GFP expression was analyzed (top row) and the 3D masks used to delimit the region in which the intensity of GFP immunosignal was measured (bottom row). B, Quantification of the intensity of GFP immunosignal in serotonergic neurons of TM- and vehicle-treated mice analyzed 30 days after the end of the treatment ( $n=7$ for each treatment). Analysis was performed using the Surface tool of the Imaris Bitplane software. $\boldsymbol{C}$, Representative coronal sections immunostained for SERT showing the distribution of SERT-positive serotonergic fibers in the dorsal hippocampus, ventral hippocampus, and in the PVN of vehicle- and TM-treated mice analyzed 30 days after the end of the treatment. Data were analyzed using Wilcoxon signed rank for paired data. n.s., not significant, $p>0.05$. Scale bar, $400 \mu \mathrm{m}(\boldsymbol{A})$, $200 \mu \mathrm{m}$ (C, dorsal hippocampus and ventral hippocampus), and $150 \mu \mathrm{m}$ (C, PVN).

sured the intensity of GFP immunofluorescence within serotonergic neurons in the raphe nuclei of both TM- and vehicle-treated mice using the Surface tool of the Imaris Bitplane software (Fig. 2A). Our analysis revealed no significant differences in the intensity of GFP fluorescence between TM-treated animals and controls (Fig. 2B). We also used SERT immunostaining as an additional assay to visualize serotonergic fibers. Results confirmed the presence of abnormalities in the density of serotonergic innervation within the hippocampus and the thalamic PVN in line with the data obtained with GFP immunoreactivity analysis (Fig. 2C)

Analysis of GFP-labeled serotonergic fibers at D60 confirmed the altered innervation in animals conditionally depleted of brain serotonin, showing a serotonergic hyperinnervation in both dorsal and ventral hippocampus $\left(+28 \%\right.$ and $+41 \%$, respectively, $p<0.01$; Fig. $\left.1 D^{\prime}, E^{\prime}\right)$, and a reduction of fiber density in thalamic PVN $(-15 \%$, $p<0.05$; Fig. $\left.1 F^{\prime}\right)$. Moreover, in line with these findings, TM-treated mice also showed an increased density of 


\section{A}

$\square$ vehicle

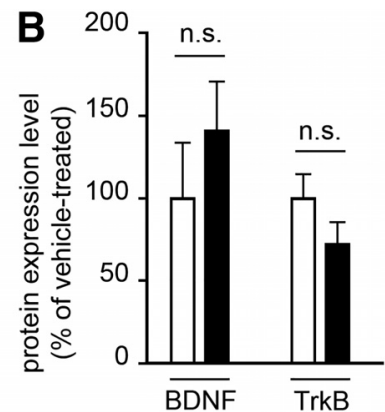

Figure 3. Serotonin depletion in TM-treated mice does not affect the hippocampal expression of BDNF and TrkB. A, Quantification of BDNF mRNA expression in the hippocampus of TM- and vehicle-treated mice 30 days after the end of the treatment. The quantification was performed by densitometric analysis of autoradiograms resulting from radioactive ISH experiments $(n=4$ for each treatment). $\boldsymbol{B}$, BDNF and TrkB protein expression level evaluated by Western blot analysis in the hippocampus of TMand vehicle-treated mice $(n=3$ TM-treated, $n=4$ vehicle-treated mice) 30 days after the end of the treatment. GADPH and $\alpha$-tubulin were used to normalize for variations on loading and transfer. Data are expressed as percentage of control (mean \pm SEM). Student's $t$ test was used as test of significance. CA, Ammon's horn; DG, dentate gyrus; n.s., not significant, $p>0.05$.

serotonergic fibers in the nucleus accumbens and a reduction at the level of the suprachiasmatic nucleus (data not shown), mirroring what has been reported in Tph2 ${ }^{\text {GFP }}$ mutants (Migliarini et al., 2013).

To investigate whether the increased density of serotonergic fibers in the hippocampus could be linked to an increase in the hippocampal brain-derived neurotrophic factor (BDNF) regulation that is known to be influenced by serotonin signaling (Hill et al., 2011; Migliarini et al., 2013; Homberg et al., 2014; Kronenberg et al., 2016), we analyzed $B D N F$ mRNA expression levels performing ISH using ${ }^{35} \mathrm{~S}$-radiolabeled antisense $B D N F$ probe on brain coronal sections of both TM- and vehicle-treated Tph2 $2^{\text {GFPfflox:: }}$ $C M V C r e E R^{T}$ mice at D30. Densitometric analysis of autoradiographic signal revealed that serotonin depletion did not impact BDNF mRNA transcriptional regulation (Fig. $3 A$ ). In an additional set of experiments, we used Western blot analysis to assess the levels of BDNF and its receptor, TrkB. We found no significant correlation between either BDNF or TrkB protein level and serotonin depletion during adulthood (Fig. 3B).

\section{Reestablishing serotonin signaling rescues serotonergic innervation defects in 5-HT-depleted mice}

We next explored the possibility that the serotonergic innervation defects observed in TM-treated Tph2 ${ }^{\text {GFP/flox:: }}$ CMVCreER $R^{T}$ animals could be reverted by restoring $5-\mathrm{HT}$ signaling via administration of the serotonin precursor 5-HTP. First, we set up a protocol of 5-HTP administration to assess the efficiency of 5-HTP treatment in bypassing the rate-limiting step of serotonin synthesis in Tph2deficient animals. To this aim, as in $T p h 2^{f l o x}$ line a residual level of serotonin is maintained (Pelosi et al., 2015), we used Tph $2^{\text {GFP }}$ mutant mice that are devoid of brain serotonin (Migliarini et al., 2013). We found that one-day 5-HTP treatment combining two $20 \mathrm{mg} / \mathrm{kg}$ intraperitoneal injections and $300 \mathrm{mg} / \mathrm{kg}$ in drinking water was sufficient to readily detect serotonergic immunoreactivity in the raphe region as well as in serotonergic terminals of Tph $2^{\text {GFP }}$ mutant mice as compared with saline-treated ones (Fig. 4).

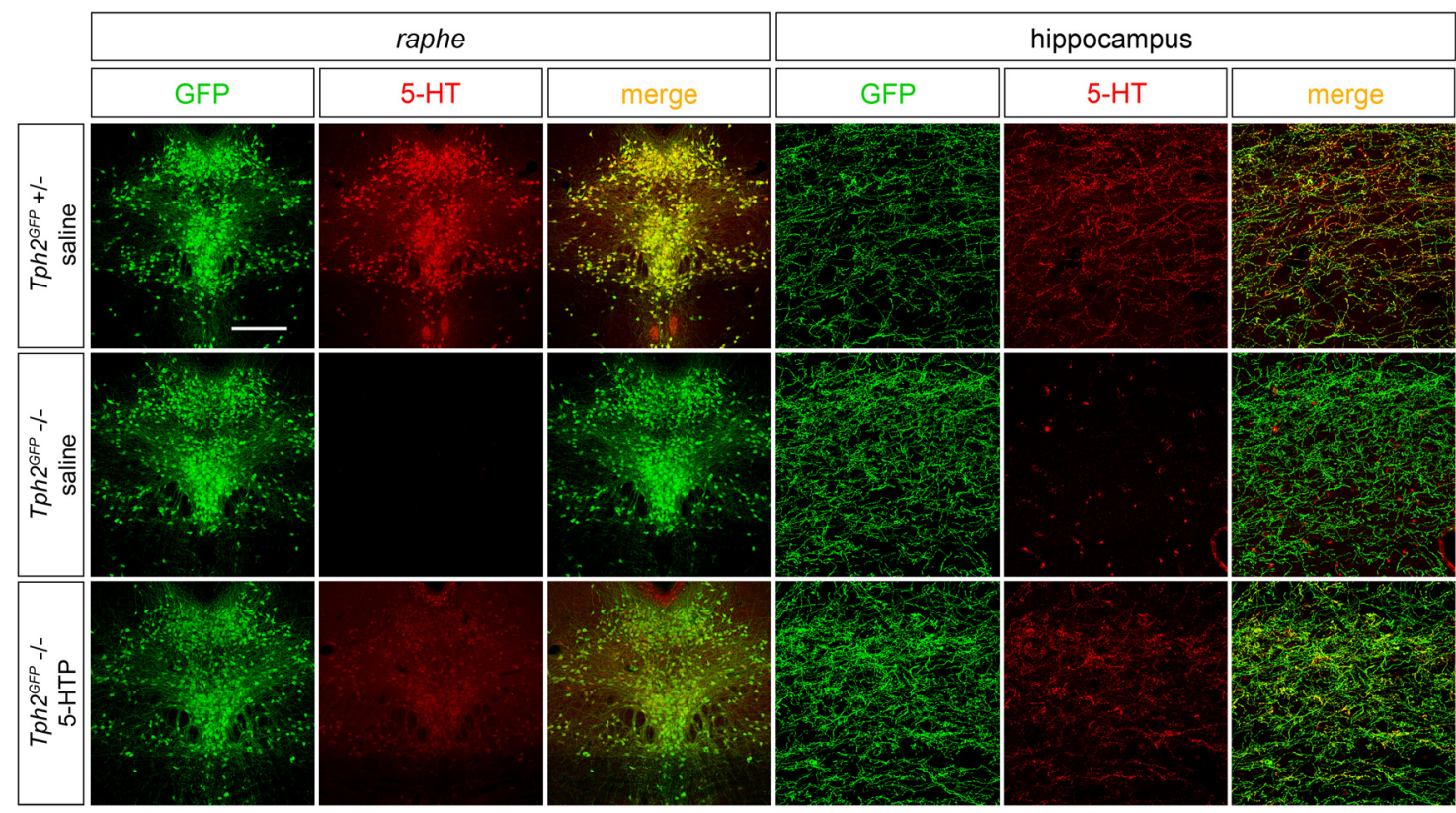

Figure 4. 5-HTP treatment restores serotonin immunoreactivity in the brain of Tph2 ${ }^{G F P}$ mutants. Representative images highlighting the reestablishment of $5-\mathrm{HT}$ immunoreactivity within serotonergic neurons and fibers of Tph2 ${ }^{\text {GFP }}$ mutant mice following $24 \mathrm{~h}$ of 5 -HTP treatment. Tph $2^{\text {GFP }}+/-$ animals treated with saline were used as controls. Scale bar, $350 \mu \mathrm{m}$ (left panels) and $60 \mu \mathrm{m}$ (right panels). 
A
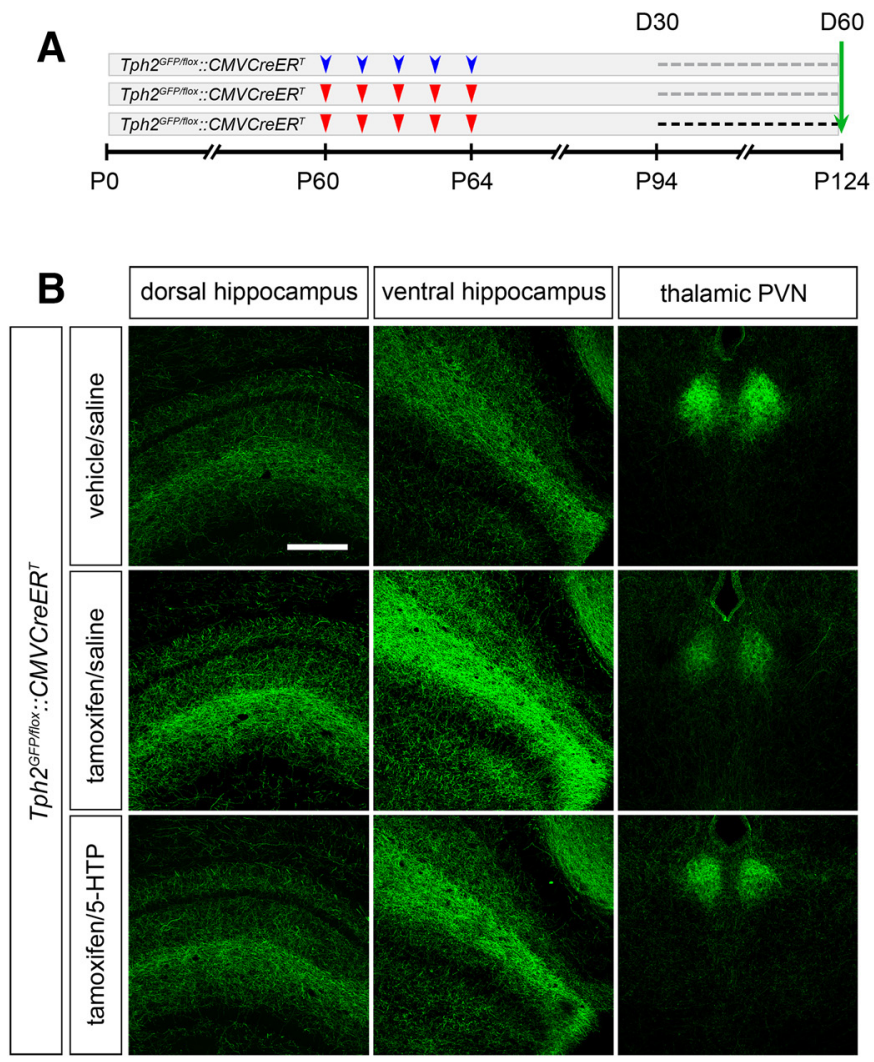

\section{thalamic PVN}
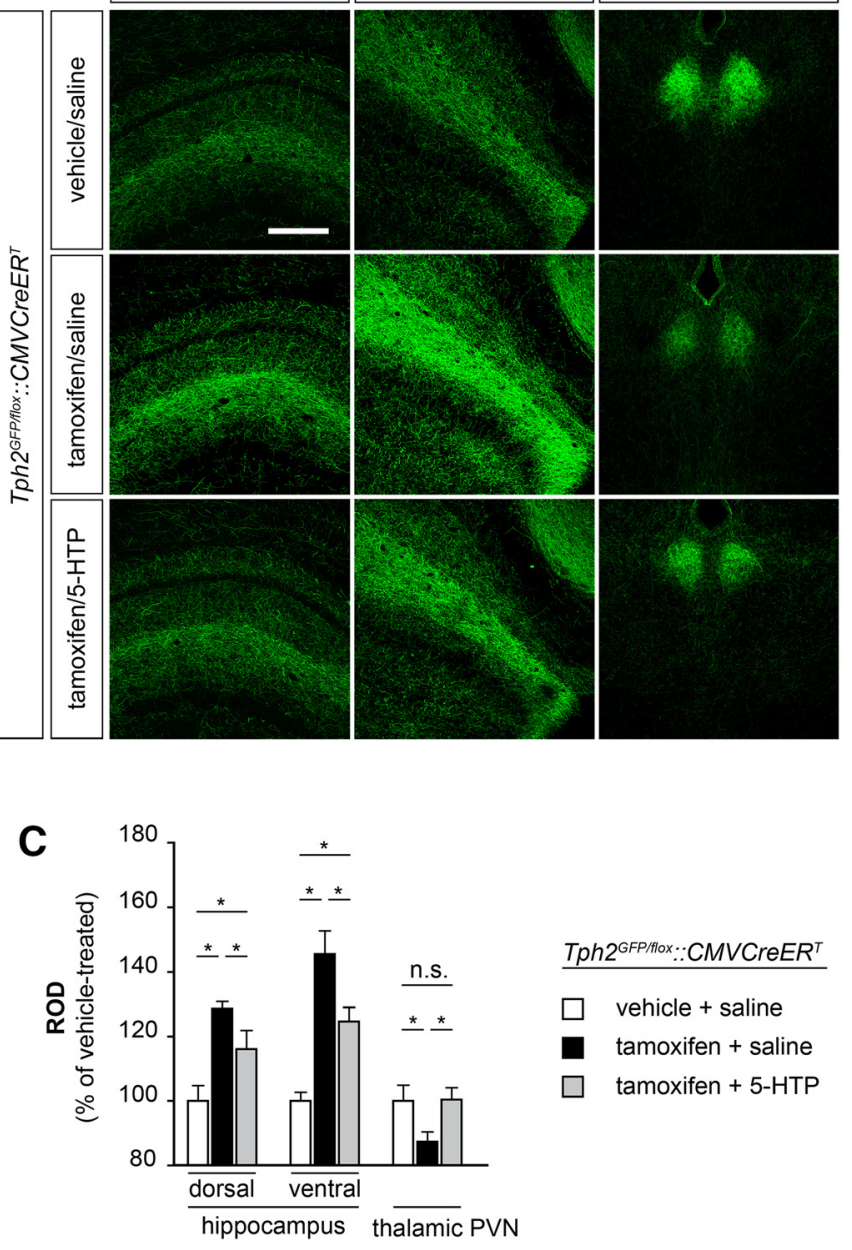
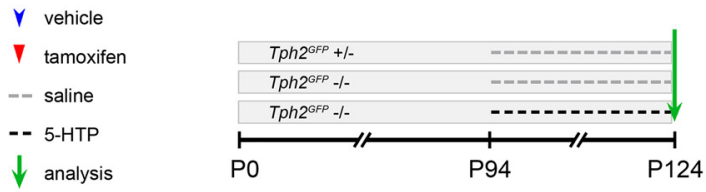
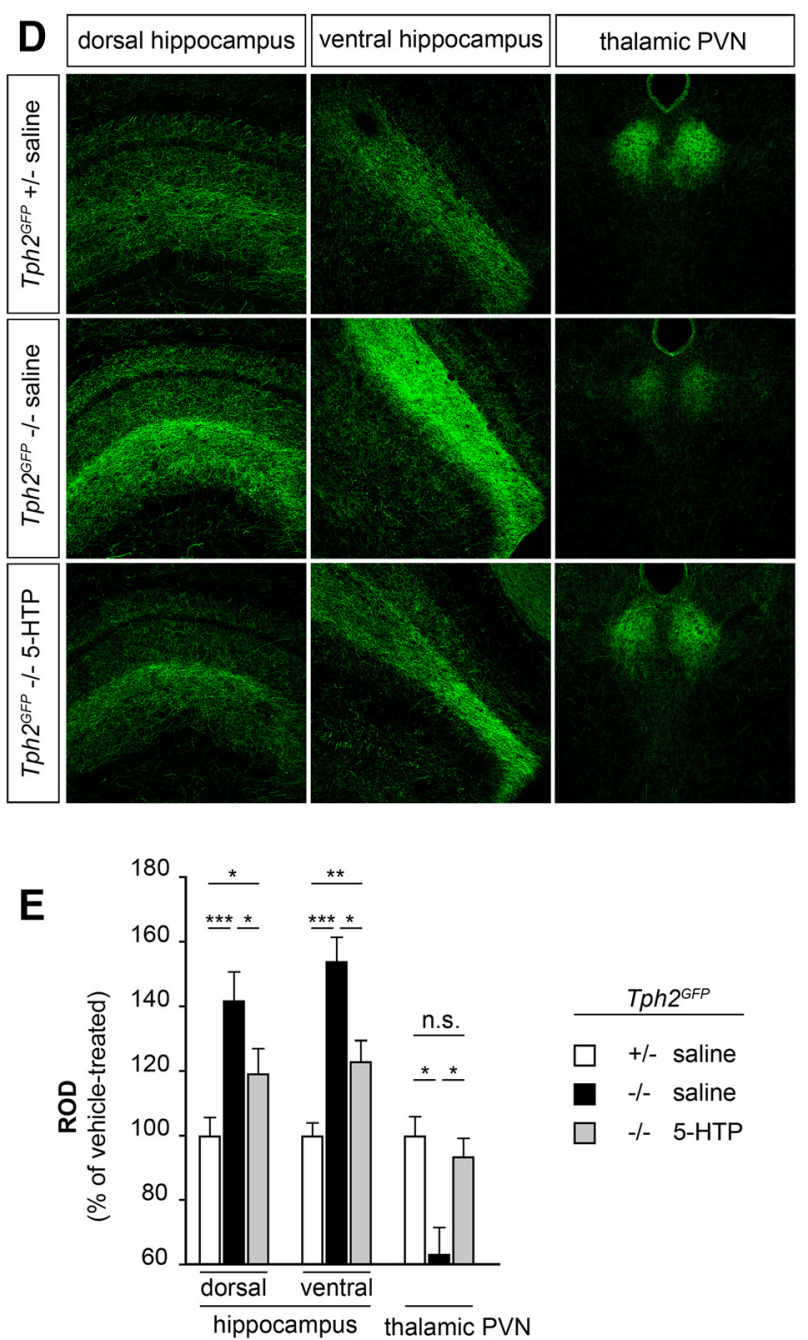

Figure 5. Reestablishing serotonin signaling in Tph2-deficient mice impacts on serotonergic fiber density and compensate alterations

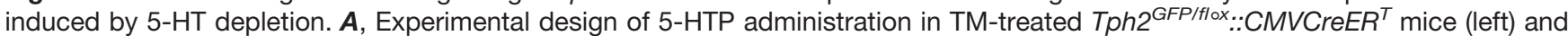
in Tph2 ${ }^{G F P}$ mutant mice (right). $\boldsymbol{B}, \boldsymbol{D}$, Representative confocal images illustrating the distribution and density of serotonergic fibers in the hippocampus and in the thalamic PVN. C, $\boldsymbol{E}$, Quantification by ROD measurements of serotonergic fiber density in the hippocampus and the thalamic PVN. Data are presented as percentage increase/decrease of ROD values as compared with vehicle/saline-treated Tph2 ${ }^{G F P / f l o x}:: C M V C r e E R^{T}$ controls $\left(n=7\right.$ for treatment) or to saline-treated Tph $2^{G F P}+/-$ mice $(n=6$ for treatment) \pm SEM. Data were analyzed using the Friedman test followed by the Wilcoxon signed rank test and the Bonferroni's correction was applied. $* * * p<0.001 ; * * p<0.01 ; * p<0.05$; n.s., not significant, $p>0.05$. Scale bar, $350 \mu \mathrm{m}$.

We then tested whether the reestablishment of serotonin signaling could rescue the alterations of serotonergic innervation induced in Tph2 ${ }^{\text {GFP/flox }}:$ :CMVCreER $R^{T}$ animals following TM treatment. Tph2 ${ }^{\text {GFP/flox }:: C M V C r e E R^{T}}$ mice that had received the 5-days TM treatment starting at P60 to deplete serotonin synthesis were then administered at D30 (namely P94) with either saline (i.e. TM/saline) or 5 -HTP (i.e. TM/5-HTP) for the following 30 days (Fig. $5 A)$. Immunohistochemical analyses confirmed in both dorsal and ventral hippocampus as well as in the thalamic
PVN of Tph2 ${ }^{\text {GFP/flox.::CMVCreER }}{ }^{T}$ TM-treated mice that received saline the presence of an aberrant serotonergic innervation in line with that described in Figure 1 (Fig. 5B). Quantitative analysis by ROD measurements showed a $28 \%$ $(p<0.05)$ and $45 \%(p<0.05)$ increase of serotonergic fiber density in dorsal and ventral hippocampus, and a 13\% $p<$ $0.05)$ decrease in the thalamic PVN as compared with control animals, respectively (Fig. 5C). Strikingly, GFP-positive serotonergic fibers in Tph2 ${ }^{\mathrm{GFP} / \text { /flox.::CMVCreER }}{ }^{T}$ TM-treated animals appeared less packed in both dorsal and ventral 
hippocampus following 30 days of 5-HTP treatment as compared with their saline-treated controls (Fig. 5B). In parallel, we observed a noticeable increase in the complexity of GFP fibers in the thalamic PVN of 5-HTP-treated mice as compared with control animals (Fig. 5B). Consistently, ROD measurements highlighted a significant reduction in serotonergic terminal density of TM/5-HTP mice in the dorsal $(-13 \%, p<$ 0.05 ; Fig. $5 C)$ and ventral $(-21 \%, p<0.05$; Fig. $5 C)$ hippocampus and $a+13 \%(p<0.05)$ increase in the thalamic $\mathrm{PVN}$, as compared with TM/saline controls (Fig. $5 C$ ).

In light of these results, we next asked whether the reestablishment of the serotonergic signaling could have an impact on the 5- $\mathrm{HT}$ innervation of animals that are life-long depleted in brain $5-\mathrm{HT}$ such as the Tph2 ${ }^{\text {GFP }}$ mutant mice. To address this question we submitted 3 months old Tph2 ${ }^{\text {GFP }}$ mutant mice to our 5-HTP administration protocol. Interestingly, following 30 days of 5-HTP treatment, we observed a reduction of the serotonergic innervation abnormalities previously described in Tph $2^{\mathrm{G} F P}$ mutant mice (Fig. 5D). Analysis in both dorsal and ventral hippocampus highlighted a 22\% $(p<0.05)$ and $31 \%(p<$ $0.05)$ reduction of fiber density in 5-HTP-treated Tph $2^{\text {GFP }}$ mutants as compared with saline-treated controls (Fig. $5 E$ ). In line, reestablishment of serotonin signaling was sufficient to restore a proper serotonergic innervation in the thalamic PVN of 5-HTP-treated Tph $2^{\text {GFP }}-/-$ mice as compared with saline-treated mutant animals $(+32 \%, p<$ 0.05; Fig. $5 D, E$.

Taken together, our data suggest that the serotonergic system retains a lifelong plasticity allowing it to respond to transient alterations in brain serotonin homeostasis and resulting in changes of fiber density in the target areas. Moreover, results showed that innervation defects observed in 5-HT-depleted mice can be significantly rescued by 5 -HTP treatment capable to reestablish serotonin levels.

\section{The depletion/reestablishment of 5-HT signaling in adult brains affects the sprouting of serotonergic fibers}

Since we demonstrated that 5-HT signaling abrogation/ reestablishment deeply affects the density of $5-\mathrm{HT}$ fibers innervating the hippocampus, we next wanted to decipher which morphologic rearrangements in the architecture of 5-HT axons are responsible for the observed alterations in

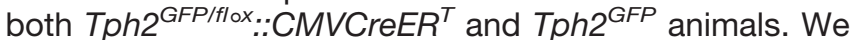
hypothesized that both an enlargement in axon diameter, and/or an active axon sprouting resulting in an increased complexity of serotonergic innervation could account for the higher density of 5-HT fibers we have observed, while both diminished axon diameter and/or branching regression could explain the fiber density reduction.

To test this hypothesis we analyzed high-magnification confocal image acquisitions of GFP-labeled 5-HT fibers in the stratum lacunosum moleculare of the dorsal hippocampus. Imaris software was used to generate 3D reconstructions of GFP-immunoreactive axons thus allowing an accurate computer-based quantitative and morphologic fiber analysis (Fig. 6A). Results showed no significant difference in the diameter of serotonergic fibers among the different experimental groups in either

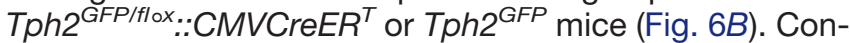
versely, a significant increase of the length of $5-\mathrm{HT}$ fibers and number of axon branch points was observed between Tph2 ${ }^{\text {GFP/flox:::CMVCreER }}{ }^{T}$ vehicle/saline- and TMsaline-treated animals resulting in $+14 \%$ axon branch point $(A B P)$ versus axon length $(A L)$ ratio $(A B P / A L$ ratio; $p<0.05$; Fig. 6B). A similar scenario was observed comparing Tph $2^{\mathrm{GFP}}+/-$ and $-/-$ saline-treated mice $(+26 \%$ ABP/AL ratio; $p<0.05$; Fig. 6B). Notably, 5-HTP administration in TM-treated Tph2 ${ }^{\text {GFP/flox }:: C M V C r e E R^{T}}$ animals promoted a decrease in the total $5-\mathrm{HT}$ fiber length and the number of branching points, bringing back the $\mathrm{ABP} / \mathrm{AL}$ ratio to the level of that observed in control mice (Fig. 6). In Tph2 ${ }^{G F P}-/-$ mice, 5-HTP treatment promoted a significant decrease of the ABP/AL ratio, although the rescue was partial (ABP/AL ratio $+17 \%$ as compared with Tph2 ${ }^{\text {GFP }}+/-$ controls; $p<0.01$; Fig. $6 B$ ). Finally, to further evaluate the consequences of changes in serotonin homeostasis on serotonergic fiber properties, we compared the tortuosity of GFP-immunoreactive fibers between control and experimental animal cohorts (Fig. $6 C)$. We found that the tortuosity index of serotonergic axons is not affected by serotonin depletion/reestablishment, suggesting that their morphologic properties are retained independently of serotonin level fluctuations (Fig. $6 C)$.

Overall, 3D reconstruction of serotonergic axon architecture and morphology quantification demonstrated that 5-HT signaling abrogation/reestablishment in adult mice can affect proper serotonergic fiber density impinging on axon branching complexity, but not on morphologic properties, by either promoting or inhibiting axon sprouting.

\section{Discussion}

This study aims to assess whether an appropriate serotonergic neurotransmission during adult life is required to preserve proper serotonergic circuitry. Here, we show that depletion of brain serotonin in adult mice produces severe abnormalities in serotonergic fiber density with a region-specific effect and that these alterations can be reversed with chronic 5-HTP administration that restores $5-\mathrm{HT}$ signaling.

To efficiently address the consequences of 5-HT depletion in adult brains, we analyzed the density of serotonergic fibers focusing on the hippocampus and the thalamic PVN that displayed diametrically opposite phenotypes in the Tph2 KO mouse model as a consequence of brain 5-HT depletion (Migliarini et al., 2013). Remarkably, we report that $5-\mathrm{HT}$ synthesis abrogation in adult Tph2 cKO mice results, after four weeks, in the alteration of serotonergic fiber density as observed by the analysis of both SERT and GFP immunoreactivity. Such a phenotype mimics the abnormalities observed in mice with a life-long depletion of brain serotonin. We also show that the changes of fiber density induced by serotonin depletion can be rescued by restoring brain 5-HT signaling in Tph2 cKO as well as in Tph2 $\mathrm{KO}$ animals. These results corroborate the hypothesis that serotonin itself acts as a modulator of serotonergic fiber density, as already proposed 

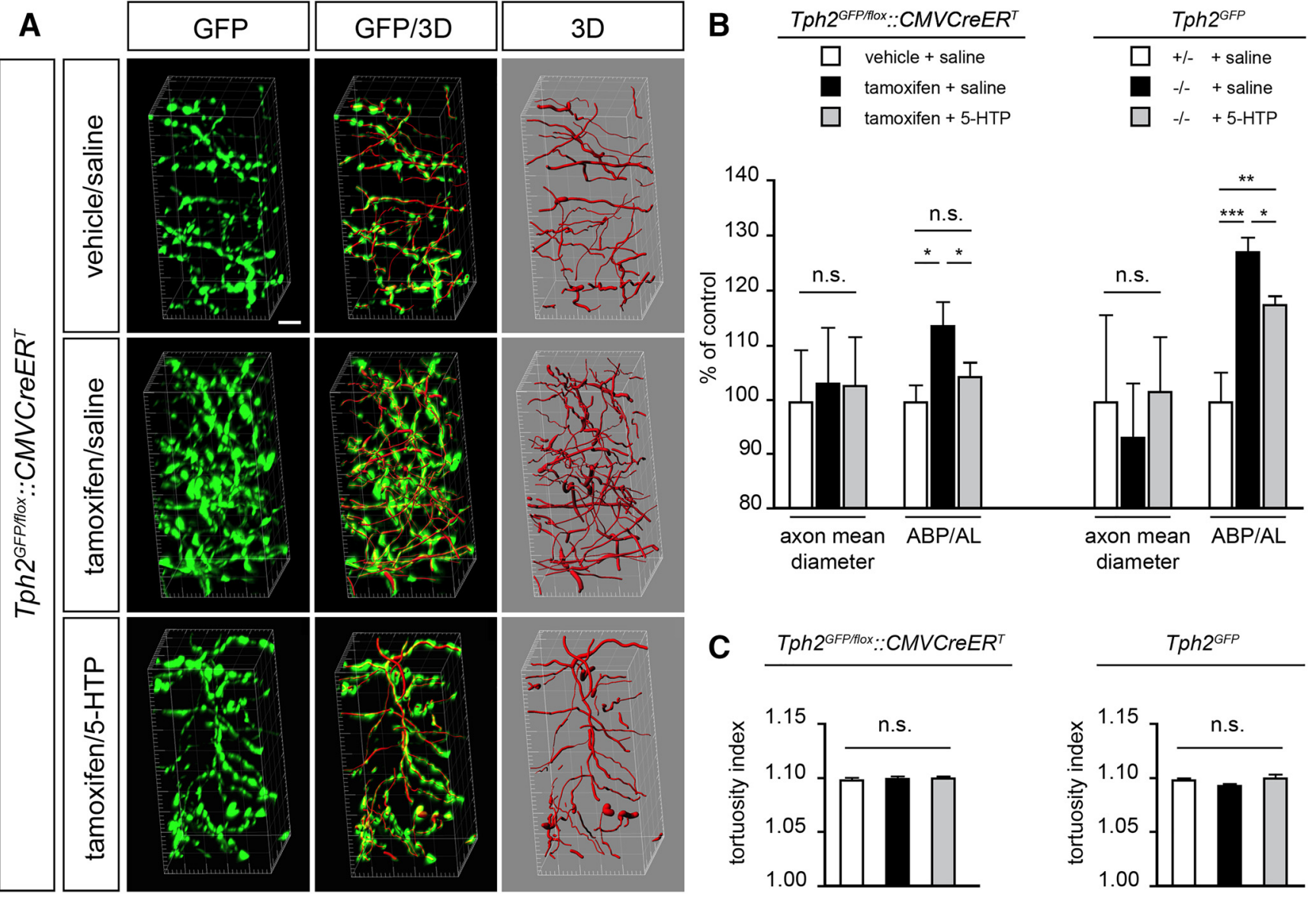

C Tph $2^{\text {GFPflox:: CMVCREERT }}$

$T p h 2^{\text {GFP }}$
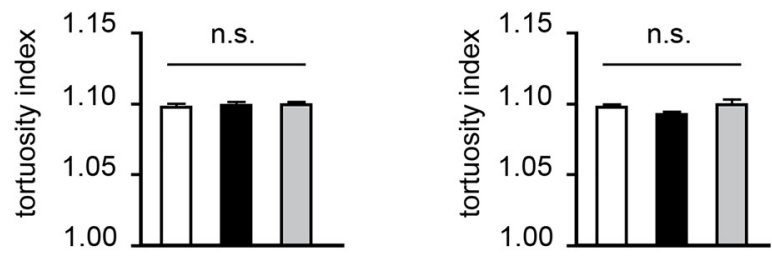

Figure 6. Computer-based mapping of serotonergic fibers and quantitative analysis of axon morphology. A, Representative high-magnification confocal acquisition in oblique view of GFP-immunoreactive serotonergic fibers (green) and computer-based 3D reconstructions (red). $\boldsymbol{B}$, Graphs showing the quantification of the axon mean diameter and the ABP/AL ratio in Tph2 ${ }^{G F P / f l o x}:$. $\operatorname{CMVCreER}^{T}$ ( $n=5$ for treatment) and Tph2 ${ }^{\text {GFP }}\left(n=5\right.$ for treatment). Data were normalized to vehicle/saline-treated Tph2 ${ }^{\text {GFP/flox.: }}$ CMVCreER $R^{T}$ controls and saline-injected Tph $2^{G F P}+/-$ controls, respectively, and presented as mean percentage increase of controls \pm SEM. $\boldsymbol{C}$, Graphs showing the average tortuosity index (defined as the length of the axon divided by the Euclidean distance between the ends or branch points) of serotonergic fibers under the different experimental conditions. Data are presented as the mean $\pm \mathrm{SEM}$. Analysis of significance was performed using the Friedman test, followed by the Wilcoxon signed rank test. $* * * p<0.001 ; * * p<0.01$; $* p<0.05$; n.s., not significant, $p>0.05$. Scale bar, $4 \mu \mathrm{m}$.

to explain the phenotype of Tph2 ${ }^{\mathrm{GFP}}$ mutants (Migliarini et al., 2013). Serotonin is known to exert a trophic autocrine activity during development and at postnatal stages when 5-HT axons sprout to innervate their targets (Lidov and Molliver, 1982). Our findings reveal that the impact of serotonin on serotonergic axon sprouting is not restricted to critical periods during the course of neurodevelopment, but it is maintained in adulthood. Altogether, the ability of serotonin to act as a regulator of serotonergic axon sprouting and the evidence that this feature is retained during adult stages of life reveal an unexpectedly high plasticity of adult serotonergic circuitry, putting forward its responsiveness to fluctuations in brain serotonin content.

Growing evidence for a structural plasticity of axons in the adult brain, defined as the ability to rearrange and sprout under specific circumstances, such as spontaneous or experience-dependent activity, has been reported in different neuronal types (De Paola et al., 2006; Stettler et al., 2006; Gogolla et al., 2007; Butz et al., 2009; Yama- hachi et al., 2009; Barnes and Finnerty, 2010; Marik et al., $2010,2013,2014)$. To date, the ability of adult serotonergic axons to undergo active sprouting has been described solely in response to physical lesions of brain or spinal cord (Zhou and Azmitia, 1984; Azmitia and WhitakerAzmitia, 1991; Zhou et al., 1995; Camand et al., 2004; Hawthorne et al., 2011; Jin et al., 2016). However, tissue lesion represents a nonphysiologic condition in which the environment is enriched with a large repertoire of molecules, which possess the ability to influence the behavior of local 5-HT fibers (Dusart et al., 1999; Camand et al., 2004; Hawthorne et al., 2011). Our findings go beyond this view showing that axonal structural plasticity represents an intrinsic property of serotonergic fibers independently of tissue damage and that plasticity of serotonergic terminals can be modulated by changes in serotonergic homeostasis. On the other hand, an intriguing question is how the manipulation of brain serotonin levels may trigger bidirectional dynamic structural rearrangements of serotonergic fibers, such as axon sprouting or reduction of 
axon arbor complexity. A tempting hypothesis is that, as reported for other neuronal types (De Paola et al., 2006; Stettler et al., 2006; Nishiyama et al., 2007), serotonergic fibers are highly dynamic in physiologic conditions undergoing continuous small rearrangements, such as branch elongation and retraction. When drastic changes in 5-HT brain levels occur, such as those induced by TM treatment in conditional Tph2 KO or by chronic 5-HTP administration, the dynamic equilibrium of $5-\mathrm{HT}$ axons is unbalanced toward either elongation or retraction, resulting in fiber sprouting or reduction of axon arbor complexity, respectively.

Another aspect that remains elusive is how serotonin depletion/reestablishment can produce diametrically opposite phenotypes of serotonergic innervation to specific structures, such as the hippocampus and the thalamic PVN. On one side, we can hypothesize that an intrinsic heterogeneity in the targets might be implied in the distinct response of serotonergic fibers to fluctuations of $5-\mathrm{HT}$ levels. Indeed, as the distribution of serotonergic receptors and their downstream effectors is highly variable in the rostral brain (Wirth et al., 2016), the response to serotonin deregulation is the outcome of the integration of signals encoded by the specific combination of receptors expressed in each target region. On the other side, it is likely that $5-\mathrm{HT}$ neurons projecting to the hippocampus and the thalamic PVN possess intrinsic differences that might contribute to the opposite effect elicited by serotonin depletion/reestablishment. Indeed, although serotonergic fibers innervating the hippocampus and the thalamic PVN manly arise from neurons of same raphe nucleus, namely the median raphe nucleus (Muzerelle et al., 2016), there is now clear evidence that a marked intrinsic heterogeneity exists even among serotonergic neurons belonging to the same anatomic domain. Indeed, distinct subtypes of 5-HT neurons that differ in their developmental origin (Jensen et al., 2008), molecular profile (Okaty et al., 2015) as well as in their electrophysiological properties and cotransmitter repertoire (Gaspar and Lillesaar, 2012; Fernandez et al., 2015) have been identified, suggesting the possibility that specific subtypes of serotonergic neurons may be specialized to mediate different biological functions. Moreover, serotonergic neurons that project to distinct forebrain regions largely belong to different serotonergic subpopulations (Fernandez et al., 2015). Based on this evidence, our observation of an opposite phenotype after serotonin depletion/reestablishment suggests that serotonergic fibers innervating the hippocampus and the thalamic PVN may arise form distinct subpopulation of median raphe 5-HT neurons. Overall, it is likely that the specific combination of serotonergic receptors in target areas along with the intrinsic properties of 5-HT neurons projecting to the same target contribute to the establishment of a regional specificity in the way changes in serotonin levels drive 5-HT fiber rearrangements.

It has been reported that modulating $5-\mathrm{HT}$ signaling by administration of either fluoxetine or agonists of 5-HT receptors facilitates the recovery of locomotion after a spinal cord injury (SCI) in rodents (Courtine et al., 2009;
Musienko et al., 2011; Scali et al., 2013). However, the precise mechanisms underlying this response are still waiting to be elucidated. In this respect, an intriguing question to address would be whether a potential role in post-SCI recovery, besides the reported action of serotonin itself, could be ascribed to serotonergic axons. In fact, because of their intrinsic capability to regrow following injury, serotonergic fibers may act as forerunners facilitating the navigation and sprouting of other types of axons through the edge of the lesion. Thus, in the future, it will be interesting to evaluate whether (1) the capability of serotonergic axons to actively sprout in response to injury and (2) the post-SCI recovery triggered by modulation of $5-\mathrm{HT}$ signaling are retained in the absence of serotonin, such as in our Tph2 cKO.

As BDNF expression has been reported to be influenced by serotonin signaling (Hill et al., 2011; Migliarini et al., 2013; Homberg et al., 2014; Kronenberg et al., 2016), we wondered whether this neurotrophin could act as a potential molecular mediator in the establishment of the observed alterations in 5-HT fiber density. However, we failed to detect any significant alteration in the hippocampal level of BDNF in our Tph2 cKO mice, suggesting that other factors are likely involved in the response of $5-\mathrm{HT}$ depletion during adult stages of life. Noteworthy, the increase of hippocampal BDNF in Tph2 mutant mice is detectable as early as P14, indicating that early phases of postnatal development represent a temporal window in which serotonin depletion can affect BDNF expression. Conversely, it is likely that the ability to influence BDNF hippocampal levels is lost in adult brains. Accordingly, the existence of specific temporal windows during postnatal development in which 5-HT signaling produces specific effects that cannot be replicated later in life has been extensively demonstrated (Gross et al., 2002; Ansorge et al., 2004, 2008; Suri et al., 2015).

On the whole, we have shown that drastic changes in brain 5-HT content during adulthood affect, in a reversible manner, serotonergic fiber density and complexity, thus providing the evidence of a direct link between 5-HT homeostasis and structural plasticity of serotonergic axons in the adult brain. In this view, it should be taken into account that also subtle changes of brain 5-HT homeostasis induced by genetic factors, pharmacological treatments, as well as environmental conditions, might impinge on serotonergic terminal sprouting, thus affecting the proper 5-HT circuitry and, potentially, interfering with its functioning.

\section{References}

Alenina N, Kikic D, Todiras M, Mosienko V, Qadri F, Plehm R, Boyé P, Vilianovitch L, Sohr R, Tenner K, Hörtnagl H, Bader M (2009) Growth retardation and altered autonomic control in mice lacking brain serotonin. Proc Natl Acad Sci USA 106:10332-10337. CrossRef Medline

Ansorge MS, Morelli E, Gingrich JA (2008) Inhibition of serotonin but not norepinephrine transport during development produces delayed, persistent perturbations of emotional behaviors in mice. J Neurosci 28:199-207. CrossRef

Ansorge MS, Zhou M, Lira A, Hen R, Gingrich JA (2004) Early-life blockade of the 5-HT transporter alters emotional behavior in adult mice. Science 306:879-881. CrossRef Medline 
Asan E, Steinke M, Lesch KP (2013) Serotonergic innervation of the amygdala: targets, receptors, and implications for stress and anxiety. Histochem Cell Biol 139:785-813. CrossRef Medline

Azmitia EC, Whitaker-Azmitia PM (1991) Awakening the sleeping giant: anatomy and plasticity of the brain serotonergic system. $\mathrm{J}$ Clin Psychiatry 52(Suppl):4-16. Medline

Barnes SJ, Finnerty GT (2010) Sensory experience and cortical rewiring. Neuroscientist 16:186-198. CrossRef

Bonnin A, Goeden N, Chen K, Wilson ML, King J, Shih JC, Blakely RD, Deneris ES, Levitt P (2011) A transient placental source of serotonin for the fetal forebrain. Nature 472:347-350. CrossRef Medline

Butz M, Wörgötter F, van Ooyen A (2009) Activity-dependent structural plasticity. Brain Res Rev 60:287-305. CrossRef Medline

Camand E, Morel MP, Faissner A, Sotelo C, Dusart I (2004) Longterm changes in the molecular composition of the glial scar and progressive increase of serotoninergic fibre sprouting after hemisection of the mouse spinal cord. Eur J Neurosci 20:1161-1176. CrossRef Medline

Cases O, Vitalis T, Seif I, De Maeyer E, Sotelo C, Gaspar P (1996) Lack of barrels in the somatosensory cortex of monoamine oxidase A-deficient mice: role of a serotonin excess during the critical period. Neuron 16:297-307. Medline

Côté F, Fligny C, Bayard E, Launay JM, Gershon MD, Mallet J, Vodjdani G (2007) Maternal serotonin is crucial for murine embryonic development. Proc Natl Acad Sci USA 104:329-334. CrossRef Medline

Courtine G, Gerasimenko Y, van den Brand R, Yew A, Musienko P, Zhong H, Song B, Ao Y, Ichiyama RM, Lavrov I, Roy RR, Sofroniew MV, Edgerton VR (2009) Transformation of nonfunctional spinal circuits into functional states after the loss of brain input. Nat Neurosci 12:1333-1342. CrossRef Medline

Daubert EA, Condron BG (2010) Serotonin: a regulator of neuronal morphology and circuitry. Trends Neurosci 33:424-434. CrossRef Medline

De Paola V, Holtmaat A, Knott G, Song S, Wilbrecht L, Caroni P, Svoboda K (2006) Cell type-specific structural plasticity of axonal branches and boutons in the adult neocortex. Neuron 49:861-875. CrossRef Medline

Dusart I, Morel MP, Wehrlé R, Sotelo C (1999) Late axonal sprouting of injured Purkinje cells and its temporal correlation with permissive changes in the glial scar. The J Comp Neur 408:399-418. Medline

Feil R, Brocard J, Mascrez B, LeMeur M, Metzger D, Chambon P (1996) Ligand-activated site-specific recombination in mice. Proc Natl Acad Sci USA 93:10887-10890. Medline

Fernandez SP, Cauli B, Cabezas C, Muzerelle A, Poncer JC, Gaspar $P$ (2015) Multiscale single-cell analysis reveals unique phenotypes of raphe 5-HT neurons projecting to the forebrain. Brain Struct Funct 221:4007-4025.

Gagnon D, Parent M (2014) Distribution of VGLUT3 in highly collateralized axons from the rat dorsal raphe nucleus as revealed by single-neuron reconstructions. PLoS One 9:e87709. CrossRef Medline

Gaspar P, Cases O, Maroteaux L (2003) The developmental role of serotonin: news from mouse molecular genetics. Nat Rev Neurosci 4:1002-1012. CrossRef Medline

Gaspar P, Lillesaar C (2012) Probing the diversity of serotonin neurons. Philos Trans R Soc Lond B Biol Sci 367:2382-2394. CrossRef Medline

Goeden N, Velasquez J, Arnold KA, Chan Y, Lund BT, Anderson GM, Bonnin A (2016) Maternal inflammation disrupts fetal neurodevelopment via increased placental output of serotonin to the fetal brain. J Neurosci 36:6041-6049. CrossRef

Gogolla N, Galimberti I, Caroni P (2007) Structural plasticity of axon terminals in the adult. Curr Opin Neurobiol 17:516-524. CrossRef Medline

Gross C, Zhuang X, Stark K, Ramboz S, Oosting R, Kirby L, Santarelli L, Beck S, Hen R (2002) Serotonin1A receptor acts during devel- opment to establish normal anxiety-like behaviour in the adult. Nature 416:396-400. CrossRef Medline

Gutknecht L, Araragi N, Merker S, Waider J, Sommerlandt FM, Mlinar B, Baccini G, Mayer U, Proft F, Hamon M, Schmitt AG, Corradetti R, Lanfumey L, Lesch KP (2012) Impacts of brain serotonin deficiency following Tph2 inactivation on development and raphe neuron serotonergic specification. PLoS One 7:e43157. CrossRef Medline

Hawthorne AL, Hu H, Kundu B, Steinmetz MP, Wylie CJ, Deneris ES, Silver J (2011) The unusual response of serotonergic neurons after CNS Injury: lack of axonal dieback and enhanced sprouting within the inhibitory environment of the glial scar. J Neurosci 31:56055616. CrossRef

Hill RA, Murray SS, Halley PG, Binder MD, Martin SJ, van den Buuse $M$ (2011) Brain-derived neurotrophic factor expression is increased in the hippocampus of $5-\mathrm{HT}(2 \mathrm{C})$ receptor knockout mice. Hippocampus 21:434-445. CrossRef Medline

Homberg JR, Molteni R, Calabrese F, Riva MA (2014) The serotoninBDNF duo: developmental implications for the vulnerability to psychopathology. Neurosci Biobehav Rev 43:35-47. CrossRef Medline

Ishimura K, Takeuchi Y, Fujiwara K, Tominaga M, Yoshioka H, Sawada T (1988) Quantitative analysis of the distribution of serotonin-immunoreactive cell bodies in the mouse brain. Neurosci Lett 91:265-270. Medline

Jensen P, Farago AF, Awatramani RB, Scott MM, Deneris ES, Dymecki SM (2008) Redefining the serotonergic system by genetic lineage. Nat Neurosci 11:417-419. CrossRef Medline

Jin Y, Dougherty SE, Wood K, Sun L, Cudmore RH, Abdalla A, Kannan G, Pletnikov M, Hashemi P, Linden DJ (2016) Regrowth of serotonin axons in the adult mouse brain following injury. Neuron 91:748-762. CrossRef Medline

Klempin F, Beis D, Mosienko V, Kempermann G, Bader M, Alenina N (2013) Serotonin is required for exercise-induced adult hippocampal neurogenesis. J Neurosci 33:8270-8275. CrossRef

Kronenberg G, Mosienko V, Gertz K, Alenina N, Hellweg R, Klempin $F$ (2016) Increased brain-derived neurotrophic factor (BDNF) protein concentrations in mice lacking brain serotonin. Eur Arch Psychiatry Clin Neurosci 266:281-284. CrossRef Medline

Lauder JM (1993) Neurotransmitters as growth regulatory signals: role of receptors and second messengers. Trends Neurosci 16: 233-240. Medline

Lidov HG, Molliver ME (1982) Immunohistochemical study of the development of serotonergic neurons in the rat CNS. Brain Res Bull 9:559-604. Medline

Marik SA, Olsen O, Tessier-Lavigne M, Gilbert CD (2013) Death receptor 6 regulates adult experience-dependent cortical plasticity. J Neurosci 33:14998-15003. CrossRef

Marik SA, Yamahachi H, McManus JN, Szabo G, Gilbert CD (2010) Axonal dynamics of excitatory and inhibitory neurons in somatosensory cortex. PLoS Biol 8:e1000395. CrossRef Medline

Marik SA, Yamahachi H, Meyer zum Alten Borgloh S, Gilbert CD (2014) Large-scale axonal reorganization of inhibitory neurons following retinal lesions. J Neurosci 34:1625-1632. CrossRef

Migliarini S, Pacini G, Pelosi B, Lunardi G, Pasqualetti M (2013) Lack of brain serotonin affects postnatal development and serotonergic neuronal circuitry formation. Mol Psychiatry 18:1106-1118. CrossRef Medline

Mosienko V, Beis D, Pasqualetti M, Waider J, Matthes S, Qadri F, Bader M, Alenina N (2015) Life without brain serotonin: reevaluation of serotonin function with mice deficient in brain serotonin synthesis. Behav Brain Res 277:78-88. CrossRef Medline

Murthy S, Niquille M, Hurni N, Limoni G, Frazer S, Chameau P, van Hooft JA, Vitalis T, Dayer A (2014) Serotonin receptor 3A controls interneuron migration into the neocortex. Nat Commun 5:5524CrossRef Medline

Musienko P, van den Brand R, Marzendorfer O, Roy RR, Gerasimenko Y, Edgerton VR, Courtine G (2011) Controlling specific locomotor behaviors through multidimensional monoaminergic 
modulation of spinal circuitries. J Neurosci 31:9264-9278. CrossRef

Muzerelle A, Scotto-Lomassese S, Bernard JF, Soiza-Reilly M, Gaspar $\mathrm{P}$ (2016) Conditional anterograde tracing reveals distinct targeting of individual serotonin cell groups (B5-B9) to the forebrain and brainstem. Brain Struct Funct 221:535-561. CrossRef Medline

Nishiyama H, Fukaya M, Watanabe M, Linden DJ (2007) Axonal motility and its modulation by activity are branch-type specific in the intact adult cerebellum. Neuron 56:472-487. CrossRef Medline

Okaty BW, Freret ME, Rood BD, Brust RD, Hennessy ML, deBairos D, Kim JC, Cook MN, Dymecki SM (2015) Multi-scale molecular deconstruction of the serotonin neuron system. Neuron 88:774791. CrossRef Medline

Pelosi B, Migliarini S, Pacini G, Pratelli M, Pasqualetti M (2014) Generation of Pet1210-Cre transgenic mouse line reveals nonserotonergic expression domains of Pet1 both in CNS and periphery. PLoS One 9:e104318. CrossRef Medline

Pelosi B, Pratelli M, Migliarini S, Pacini G, Pasqualetti M (2015) Generation of a Tph2 Conditional Knockout Mouse Line for Timeand Tissue-Specific Depletion of Brain Serotonin. PLoS One 10: e0136422. CrossRef Medline

Persico AM, Mengual E, Moessner R, Hall FS, Revay RS, Sora I, Arellano J, DeFelipe J, Gimenez-Amaya JM, Conciatori M, Marino R, Baldi A, Cabib S, Pascucci T, Uhl GR, Murphy DL, Lesch KP, Keller F (2001) Barrel pattern formation requires serotonin uptake by thalamocortical afferents, and not vesicular monoamine release. J Neurosci 21:6862-6873.

Riccio O, Potter G, Walzer C, Vallet P, Szabó G, Vutskits L, Kiss JZ, Dayer AG (2009) Excess of serotonin affects embryonic interneuron migration through activation of the serotonin receptor 6 . Mol Psychiatry 14:280-290. CrossRef Medline

Ruhé HG, Mason NS, Schene AH (2007) Mood is indirectly related to serotonin, norepinephrine and dopamine levels in humans: a metaanalysis of monoamine depletion studies. Mol Psychiatry 12:331359. CrossRef Medline
Savelieva KV, Zhao S, Pogorelov VM, Rajan I, Yang Q, Cullinan E, Lanthorn TH (2008) Genetic disruption of both tryptophan hydroxylase genes dramatically reduces serotonin and affects behavior in models sensitive to antidepressants. PLoS One 3:e3301. CrossRef Medline

Scali $M$, Begenisic $T$, Mainardi $M$, Milanese $M$, Bonifacino $T$, Bonanno G, Sale A, Maffei L (2013) Fluoxetine treatment promotes functional recovery in a rat model of cervical spinal cord injury. Sci Rep 3:2217. CrossRef

Scott GD, Fryer AD, Jacoby DB (2013) Quantifying nerve architecture in murine and human airways using three-dimensional computational mapping. Am J Respir Cell Mol Biol 48:10-16. CrossRef Medline

Stettler DD, Yamahachi H, Li W, Denk W, Gilbert CD (2006) Axons and synaptic boutons are highly dynamic in adult visual cortex. Neuron 49:877-887. CrossRef Medline

Suri D, Teixeira CM, Cagliostro MK, Mahadevia D, Ansorge MS (2015) Monoamine-sensitive developmental periods impacting adult emotional and cognitive behaviors. Neuropsychopharmacology 40:88-112. CrossRef

Wallace JA, Lauder JM (1983) Development of the serotonergic system in the rat embryo: an immunocytochemical study. Brain Res Bull 10:459-479. Medline

Wirth A, Holst K, Ponimaskin E (2016) How serotonin receptors regulate morphogenic signalling in neurons. Prog Neurobiol 151: 35-56.

Yamahachi H, Marik SA, McManus JN, Denk W, Gilbert CD (2009) Rapid axonal sprouting and pruning accompany functional reorganization in primary visual cortex. Neuron 64:719-729. CrossRef Medline

Zhou FC, Azmitia EC (1984) Induced homotypic collateral sprouting of serotonergic fibers in the hippocampus of rat. Brain Res 308: 53-62. Medline

Zhou FC, Azmitia EC, Bledsoe S (1995) Rapid serotonergic fiber sprouting in response to ibotenic acid lesion in the striatum and hippocampus. Brain Res Dev Brain Res 84:89-98. Medline 